\title{
The bizarre imagery effect and intention to learn
}

\author{
DANIEL J. BURNS \\ Union College, Schenectady, New York
}

\begin{abstract}
The bizarre imagery effect, better memory for bizarre stimuli than for common stimuli, is now an established finding. However, the mnemonic benefits of bizarre imagery are subject to several constraints (e.g., the use of mixed lists and free-recall tests). A further constraint on the bizarreness effect is demonstrated here. In each of two experiments, subjects were given either incidental or intentional study instructions and were asked to rate the vividness of the images they formed from the bizarre and common sentences. Contrary to conclusions based on available evidence, the bizarreness effect in free recall was manifested only with the incidental learning instructions. This additional constraint on the effect is consistent with the item-order account of bizarreness.
\end{abstract}

A generally accepted view of imagery is that bizarre images lead to better retention performance than common images. Until fairly recently, however, there was little empirical support for this belief. This lack of empirical support for the mnemonic benefits of bizarre imagery led Postman (1975) to conclude that " despite popular misconceptions, bizarre images are no better as memory aids than common ones" (p. 322). More recently, however, Einstein and McDaniel (1987) reviewed the bizarre imagery literature and demonstrated that the effect does manifest itself under certain experimental conditions: namely, when mixed lists are used and retention is assessed with a free-recall test (see also Cox \& Wollen, 1981; McDaniel \& Einstein, 1986).

McDaniel and his colleagues have drawn from research on the generation effect-better memory for self-generated items than for items that are simply read - to explain the effects of list type (mixed or unmixed) on the bizarreness effect (McDaniel, Einstein, DeLosh, May, \& Brady, 1995). Similar to the bizarreness effect, the generation effect generally does not occur with unmixed list designs (see, e.g., Slamecka \& Katsaiti, 1987). One explanation for the absence of generation effects with unmixed lists is based on the item-order distinction. Presumably, generation enhances the encoding of item-specific information but at the expense of processing serial order information (Burns, Curti, \& Lavin, 1993; Nairne, Riegler, \& Serra, 1991; Serra \& Nairne, 1993). The additional item information given to the generated items tends to improve recall by about the same amount as the additional order information improves recall for the simply read items, thus resulting in a null effect. When mixed lists are used, however, the simply read items either do not receive the additional order processing or the order processing spreads

This research was supported by a faculty research grant to D.J.B. from Union College. I thank Teresa Hanlon for her help in collecting and scoring the data reported in Experiment 1, and Gilles Einstein, John Gardiner, and Matt Serra for their helpful comments. Correspondence should be addressed to D. Burns, Department of Psychology, Union College, Schenectady, NY 12308 (e-mail: burns@gar.union.edu). to nearby generated items. This results in better recall for the generated items because all the items receive roughly equivalent amounts of order processing, but the generated items receive more item processing.

McDaniel et al. (1995) have argued that in betweenlists designs, bizarre sentences enhance the processing of item information, and hinder the processing of order information, much like self-generated items. This processing tradeoff tends to result in a null effect with unmixed lists. However, in mixed-list designs both types of sentences receive roughly equivalent amounts of order processing, so the bizarre sentences are recalled better due to the additional item processing.

One variable that has been manipulated in the generation effect literature is intention to learn--the generation advantage with mixed-lists designs is larger under conditions of incidental learning than with intentional learning instructions (Watkins \& Sechler, 1988). In addition, with unmixed lists nearly every demonstration of a freerecall generation effect has been with incidental instructions (see, e.g., Burns, in press; McDaniel, Waddill, \& Einstein, 1988). There have been several reported failures to obtain the effect with unmixed lists under conditions of intentional learning (see, e.g., Burns, 1990, 1992, in press; McDaniel et. al., 1988; Nairne et al., 1991; Serra \& Nairne, 1993; Slamecka \& Katsaiti, 1987). Thus, intention to learn is an important variable in the generation effect literature. The item-order approach can account for the finding of a smaller generation effect with intentional than with incidental instructions in mixed-list designs. It does so by assuming that with intentional learning instructions, subjects strategically process item-specific information to a level approaching the amount given to the generated items, thus diminishing the free-recall difference (see also McDaniel et al., 1988). If the item-order processing difference underlying the generation effect also underlies the bizarreness effect, then intention to learn should also decrease the magnitude of the bizarreness advantage.

I could find only one published experiment on the bizarreness effect in which intention to learn was manipulated. Merry and Graham (1978) found that intentional 
learning instructions produced a bizarreness effect statistically equivalent to that found with incidental instructions. This result is inconsistent with the view that bizarreness and generation effects in free recall are the result of the same underlying mechanisms. However, 12year-old children were used as subjects in the Merry and Graham experiment. It is questionable whether children of that age would spontaneously use elaborative rehearsal strategies when intentionally learning material, especially after performing the mental imagery task required by Merry and Graham.

Both Wollen and Cox (1981) and Hirshman, Whelley, and Palu (1989, Experiment 5) gave adult subjects intentional learning instructions and found significant bizarreness effects. However, neither experiment included an incidental learning condition, so the magnitude of the effect under incidental and intentional conditions could not be compared. Nonetheless, the available evidence suggests that although intention to learn is an important variable for the generation effect, it is not for the bizarreness effect. This seemingly different outcome for the two effects suggests, contrary to McDaniel et al.'s (1995) hypothesis, that the two effects are not due to the same underlying mechanisms. Before this conclusion is accepted, however, type of learning instructions should be varied in the same experiment using adult subjects.

\section{EXPERIMENTS 1 AND 2}

Both Experiments 1 and 2 were 2 (type of learning instructions: incidental or intentional) $\times 2$ (type of sentence: bizarre or common) mixed factorials, with the latter factor manipulated within lists. Experiment 2 was a direct replication of Experiment 1, but with a different set of common and bizarre sentences.

\section{Method \\ Subjects. There were 24 subjects tested in each between-subjects condition of Experiment 1 and 16 tested in each condition of Experi- ment 2. The subjects were students at Union College who were paid $\$ 4.00$ for their participation and who were tested in groups of 6 or fewer.}

Materials and Procedure. The common and bizarre sentences were selected from McDaniel and Einstein (1986). The 12 common and 12 bizarre sentences used in Experiment 1 were taken from McDaniel and Einstein's Set 1 . These were the same sentences used in the Hirshman et al. (1989) study, in which a bizarreness effect was obtained with intentional instructions. The 12 sentences used in Experiment 2 were taken from McDaniel and Einstein's Set 2. Each sentence was typed on an approximately $3 \times 5$ in. card and contained three nouns, which were underlined. Each subject was presented a list of six common and six bizarre sentences. The six common sentences for half of the subjects were presented in bizarre form for the other half of the subjects and vice versa. In addition, in Experiment 1, two different random orders of sentence presentation were used, each given to half of the subjects. Only one order was used in Experiment 2.

All subjects were instructed that they were participating in an experiment studying imagery ability. All subjects were instructed that they would be required to read 12 sentences containing three underlined nouns. Their task was to form a mental image containing the three underlined words, and then to rate the vividness of that image on a 5-point scale. Subjects in the incidental learning group were told that the relationship between their imagery ability and their ability to solve problems was being measured. They were led to believe that they would be given five insight problems to solve following the imagery rating task. Subjects in the intentional learning group were told that their imagery ability would be related to their ability to remember the underlined words in the sentences.

Subjects self-presented the sentences at a $10-\mathrm{sec}$ rate, recording their vividness ratings on a ratings sheet containing 12 blank lines. Immediately following sentence presentation, subjects were given approximately $1 \mathrm{~min}$ of simple addition problems, which served as distractor activity. Then subjects were given a 4-min free-recall test in which they attempted recall of all of the underlined words. Following the recall test, subjects in the incidental learning instructions group of Experiment 2 were asked whether they had expected their memory for the sentences to be tested. None of the subjects reported expecting the memory test.

\section{RESULTS}

\section{Experiment 1}

The free-recall results are presented in Table 1. As can be seen, the bizarreness effect appears to have occurred only when incidental instructions were given. A 2 (study instructions: incidental or intentional) $\times 2$ (sentence type: bizarre or common) mixed factor analysis of variance (ANOVA) was performed on the recall scores. The ANOVA revealed that the main effect of sentence type was significant at the $p<.05$ level $\left[F(1,46)=6.16, M S_{\mathrm{e}}=12.51\right]$, as was the interaction $\left[F(1,46)=5.88, M S_{\mathrm{e}}=12.51\right]$. The main effect of study instructions was not significant $(F<1)$. Individual comparisons revealed that items from the bizarre sentences were recalled better than were items from the common sentences under incidental learning conditions $\left[F(1,23)=12.87, M S_{\mathrm{e}}=11.69\right]$, but not under intentional learning conditions $(F<1)$.

The bizarreness effect is usually associated with subjects recalling items from a greater number of bizarre sentences, not with better recall of the individual nouns within each sentence (e.g., McDaniel \& Einstein, 1986). A sentence was scored as accessed if at least one target word from that sentence was recalled. The sentence access and items per sentence recall scores are presented in

Table 1

Mean Performance Measures for the Four Conditions of Each Experiment

\begin{tabular}{|c|c|c|c|c|}
\hline \multirow[b]{3}{*}{$\begin{array}{c}\text { Performance } \\
\text { Measure }\end{array}$} & \multicolumn{4}{|c|}{ Study Instructions } \\
\hline & \multicolumn{2}{|c|}{ Incidental Learning } & \multicolumn{2}{|c|}{ Intentional Learning } \\
\hline & $\begin{array}{c}\text { Bizarre } \\
\text { Sentences } \\
\end{array}$ & $\begin{array}{l}\text { Common } \\
\text { Sentences }\end{array}$ & $\begin{array}{c}\text { Bizarre } \\
\text { Sentences }\end{array}$ & $\begin{array}{l}\text { Common } \\
\text { Sentences }\end{array}$ \\
\hline \multicolumn{5}{|c|}{ Experiment 1} \\
\hline Free recall & 10.00 & 6.46 & 8.33 & 8.29 \\
\hline Sentence access & 3.96 & 2.42 & 3.71 & 3.50 \\
\hline Items per sentence & 2.39 & 2.65 & 2.24 & 2.33 \\
\hline \multicolumn{5}{|c|}{ Experiment 2} \\
\hline Free recall & 8.75 & 6.56 & 7.50 & 8.94 \\
\hline Sentence access & 3.50 & 2.69 & 3.19 & 3.50 \\
\hline Items per sentence & 2.53 & 2.46 & 2.40 & 2.59 \\
\hline
\end{tabular}

Note-Dividing the mean free-recall scores by the mean sentence access scores produces mean items per sentence scores different from those reported. The reason for this difference is that the reported scores were calculated at the individual subject level. 
Table 1 . The $2 \times 2$ ANOVA performed on the sentence access scores showed that more of the bizarre sentences than common sentences were accessed $\left[F(1,46)=12.62, M S_{\mathrm{e}}=\right.$ 1.46]. The interaction was also significant $[F(1,46)=7.33$, $\left.M S_{\mathrm{e}}=1.46\right]$. Type of study instructions did not significantly influence sentence access $\left[F(1,46)=3.26, M S_{\mathrm{e}}=\right.$ 1.28]. Paralleling the free-recall results, individual comparisons revealed that more bizarre sentences than common sentences were accessed, but only for the incidental instructions groups $\left[F(1,23)=21.17, M S_{\mathrm{e}}=1.35\right]$, not for the intentional instructions groups $(F<1)$.

The $2 \times 2$ ANOVA performed on the number of items recalled per sentence revealed that more items were recalled from the common sentences than from the bizarre sentences $\left[F(1,46)=5.83, M S_{\mathrm{e}}=0.13\right]$. No other effects were significant (largest $F=2.79$ ).

\section{Experiment 2}

The $2 \times 2$ ANOVA conducted on the free-recall scores of Experiment 2, shown in Table 1, revealed that only the interaction was significant $\left[F(1,30)=8.66, M S_{\mathrm{e}}=6.07\right]$. Neither main effect approached significance (both $F \mathbf{s}<$ 1). Individual comparisons revealed that the bizarre items were recalled better than the common items were for the incidental learning condition $[F(1,15)=7.25$, $\left.M S_{\mathrm{e}}=5.28\right]$, but the advantage for the common items following intentional learning instructions was not significant $\left[F(1,15)=2.41, M S_{\mathrm{e}}=6.86\right]$.

The $2 \times 2$ ANOVA performed on the sentence access scores, shown in Table 1, revealed that only the interaction was significant $\left[F(1,30)=5.44, M S_{\mathrm{e}}=1.07\right]$. Neither main effect was significant (both $F \mathrm{~s}<1$ ). Individual comparisons showed that the bizarre items produced greater sentence access than did the common items under incidental learning conditions $\left[F(1,15)=6.48, M S_{\mathrm{e}}=\right.$ 0.81 ], but not under intentional learning conditions $(F<$ 1). The $2 \times 2$ ANOVA performed on the items recalled per sentence data, displayed in Table 1, revealed that only the interaction was significant $\left[F(1,30)=5.19, M S_{\mathrm{e}}=\right.$ 0.92 ; both other $\left.F_{\mathrm{s}}<1\right]$. The follow-up tests revealed that the small advantage for the common items in the intentional learning group was significant $[F(1,15)=5.63$, $\left.M S_{\mathrm{e}}=0.05\right]$, but the small advantage for the bizarre items following incidental instructions was not significant $(F<1)$.

\section{DISCUSSION}

Contrary to conclusions based on the available evidence, the size of the bizarreness effect in free recall is dependent on type of learning instructions: In both experiments, the bizarreness effect was eliminated when intentional learning instructions were given. Consistent with earlier research, the free-recall advantage for the bizarre sentences for the incidental learning group resulted from greater sentence access, not greater within-sentence recall (e.g., McDaniel \& Einstein, 1986).

The free-recall results parallel those found with the generation effect. As stated in the introduction, the generation effect is larger with incidental than with intentional instructions (Watkins \& Sechler, 1988; see also Burns, in press; McDaniel et al., 1988). The available evidence had suggested that intention to learn did not have an analogous influence on the bizarreness effect. However, the present results demon- strate a parallel between the two effects, where prior research suggested a divergence. The current pattern strengthens McDaniel et al.'s (1995) argument that differences in item and order processing underlie both phenomena.

The absence of a bizarreness effect with intentional learning instructions is not consistent with the results of Wollen and Cox (1981) or Hirshman et al. (1989), who found significant bizarreness effects with intentional learning instructions. This discrepancy might be due to one of the several procedural differences between the experiments. The point made here, however, is not whether the bizarreness effect can be produced under conditions of intentional learning, but rather that the effect is larger under conditions of incidental learning.

It is known that the bizarreness effect is diminished when subjects are required to elaborate on the sentences at encoding. McDaniel and Einstein (1986) eliminated the bizarreness effect by requiring subjects to perform semantic processing on the common and bizarre sentences. Similarly, Robinson-Riegler and McDaniel (1994) showed that the effect was diminished when complex sentences, which presumably produced elaborate encodings, were used (see also McDaniel \& Einstein, 1989). If one assumes that intentional learning instructions foster elaborative rehearsal of the items (see Hyde \& Jenkins, 1973), the present results are consistent with these findings.

The conditions under which the bizarreness effect is obtainable are quite constrained. It occurs only when mixed lists are used and retention is tested with free recall, and then only when low-complexity sentences are used. In addition, the present experiment suggests that subjects must be unaware of the impending memory test. The latter finding is inconsistent with the views of professional mnemonists who have long professed the mnemonic benefits of bizarre imagery (see, e.g., Lorayne \& Lucas, 1974). The present results suggest that bizarre imagery can improve retention, but that it is less likely to do so under the intentional learning conditions used by mnemonists.

Considering the excessive constraints on the bizarreness effect, the usefulness of bizarre imagery as a mnemonic technique is questionable. This does not imply, however, that the effect is theoretically unimportant. Rather, the bizarreness effect can be viewed as a member of a growing class of effects (see McDaniel, DeLosh, \& Einstein, 1994) that are caused by an item-order processing tradeoff. Therefore, the bizarreness effect may serve as fertile theoretical testing ground, even if bizarreness can no longer be viewed as an aid to mnemonic techniques based on mental imagery.

\section{REFERENCES}

Burns, D. J. (1990). The generation effect: A test between single- and multifactor theories. Journal of Experimental Psychology: Learning, Memory, \& Cognition, 16, 1060-1067.

BURNS, D. J. (1992). The consequences of generation. Journal of Memory \& Language, 31, 615-633.

BURNS, D. J. (in press). The item-order distinction and the generation effect: The importance of order information in long-term memory. American Journal of Psychology.

Burns, D. J., CurTi, E. T., \& Lavin, J. C. (1993). The effects of generation on item and order retention in immediate and delayed recall. Memory \& Cognition, 21, 846-852.

Cox, S. D., \& Wollen, K. A. (1981). Bizarreness and recall. Bulletin of the Psychonomic Society, 18, 244-245.

Einstein, G. O., \& McDaniel, M. A. (1987). Distinctiveness and the mnemonic benefits of bizarre imagery. In. M. A. McDaniel \& M. Pressley (Eds.), Imagery and related mnemonic processes: Theories, individual differences and applications (pp.78-102). New York: Springer-Verlag.

Hirshman, E., Whelley, M. M., \& Palu, M. (1989). An investigation of paradoxical memory effects. Journal of Memory \& Language, 28 , 594-609.

HydE, T. S., \& Jenkins, J. J. (1973). Recall of words as a function of semantic, graphic, and syntactic orienting tasks. Journal of Verbal Learning \& Verbal Behavior, 12, 675-682.

LORAYNE, H., \& LuCAS, J. (1974). The memory book. New York: Stein \& Day.

McDaniel, M. A., Delosh, E., \& Einstein, G. O. (1994, November). 
The role of order information in free recall advantages in mixed lists. Paper presented at the 35th annual meeting of the Psychonomic Society, St. Louis.

MCDANieL, M. A., \& Einstein, G. O. (1986). Bizarre imagery as an effective memory aid. The importance of distinctiveness. Journal of Experimental Psychology: Learning, Memory, \& Cognition, 12, 54-65.

McDaniel, M. A., \& Einstein, G. O. (1989). Sentence complexity eliminates the mnemonic advantage of bizarre imagery. Bulletin of the Psychonomic Society, 27, 117-120.

McDaniel, M. A., Einstein, G. O., Delosh, E., May, C., \& Brady, P. (1995). The bizarreness effect: It's not surprising, it's complex. Jour nal of Experimental Psychology: Learning, Memory, \& Cognition, 21, 422-435.

MCDANiel, M. A., WadDill, P. J., \& Einstein, G. O. (1988). A contextual account of the generation effect: A three factor theory. Jour nal of Memory \& Language, 27, 521-536.

MERRY, R., \& GRAHAM, N. C. (1978). Imagery bizarreness in children's recall of sentences. British Journal of Psychology, 69, 315-321.

Nairne, J. S., Riegler, G. L., \& Serra, M. (1991). Dissociative effects of generation on item and order information. Journal of Experimental Psychology: Learning, Memory, \& Cognition, 17, 702-709.
Postman, L. (1975). Verbal learning and memory. Annual Review of Psychology, 26, 291-335.

Robinson-Riegler, B., \& McDaniel, M. A. (1994). Further constraints on the bizarreness effect: Elaboration at encoding. Memory \& Cognition, 22, 702-712.

SerRa, M., \& NaIRne, J. S. (1993). Design controversies and the generation effect: Support for an item-order hypothesis. Memory \& Cognition, 21, 34-40.

Slamecka, N. J., \& Katsaiti, K. T. (1987). The generation effect as an artifact of selective displaced rehearsal. Journal of Memory \& Language, 26, 589-607.

WATKINS, M. J., \& SECHLER, E. S. (1988). Generation effect with an incidental memorization procedure. Journal of Memory \& Language. 27, 537-544.

Wollen, K. A., \& Cox, S. D. (1981). The bizarreness effect in a multitrial intentional learning task. Bulletin of the Psychonomic Society, 18, 296-298

(Manuscript received August 22, 1995 revision accepted for publication December 29, 1995.)

\section{World-Wide Academic Visitor Exchange (WAVE) on the Internet}

URL: http://www.psy.uwa.edu.au/wave/

In order to facilitate international travel and exchange, a searchable database has been installed on the World Wide Web to bring travelers' itineraries to the attention of potential hosts and colloquium organizers.

Scientists about to travel abroad are encouraged to add their itinerary to the WAVE database. Colloquium organizers and other prospective hosts are encouraged to search the WAVE database for colleagues visiting their areas.

WAVE is self-explanatory, and the home page can be found at URL: http://www.psy.uwa.edu.au/wave/. Additional information can be obtained from the WAVE coordinator ( $S$. Lewandowsky) at lewan@psy.uwa.edu.au.

WAVE is a free service sponsored and maintained by the Department of Psychology at The University of Western Australia. 